\title{
An empirical assessment of recent challenges in today's financial markets
}

\author{
Joscha Beckmann; Robert L. Czudaj; and Gary Koop
}

This special issue comprises a selection of papers from the first Workshop on Financial Econometrics and Empirical Modelling of Financial Markets which took place in Bochum in April 2017 and the annual conference of the European Economics and Finance Society in Ljubljana in June 2017. The broad range of methods and topics covered in these papers reflects the aim of the workshop and the annual conference to bring together young econometricians and economists. Essentially, all papers deal with important aspects of today's financial markets and relate them to issues faced by policymakers.

The lead article contributed by Thornton (2019) deals with two of the most important puzzles in international finance relating to exchange rates: the unbiasedness puzzle - the finding of a marked difference in the conclusion about the forward rate unbiasedness hypothesis depending on whether the hypothesis is tested using the forward rate equation or forward premium equation-and the forward premium puzzle - the fact that more often than not the forward premium incorrectly predicts the direction of the subsequent change in the spot rate. Thornton (2019) proposes a solution to both puzzles by highlighting the important of persistence in spot exchange rates and a potential small sample bias for the obtained test results.

Most papers in this special issue are devoted to the analysis of up-to-date policy issues. While Thornton (2019) contributes to the debate on the well-established link between interest rate and exchange rates, Gehringer and Mayer (2019) investigate the factors determining long-term interest rates using cointegration techniques. They find that central banks have actually had a key influence on the level of long-term interest rates. Gehringer and Mayer (2019) argue that the Austrian school of economics explanation in the model of Wicksell-Mises-Hayek of the credit and business cycle adequately describes recent developments. They also point to a misalignment of market rates due to a lack of necessary knowledge and foresight to set market rates to levels consistent with economic fundamentals.

Belke and Osowski (2019) deal with an important policy issue in the context of fiscal policy. They identify and measure fiscal spillovers in EU countries empirically using a global vector autoregression (GVAR) model. To account for effects on financial markets, the set of variables also includes 10-year interest yields and exchange rates. Their empirical setting contains absolute values of fiscal spillovers in a countrywise perspective and at the time profile of the impact of fiscal shocks (via impulse response analysis). Their findings suggest moderate spillover effects of fiscal policy shocks originating in Germany and France while French spillovers are stronger on EMU than on non-EMU countries. Overall, there is a significant variation regarding the magnitude of the spillovers on individual destination countries and country clusters.

The international connectedness of financial markets materializes in several ways. After the changes in US policy and the Brexit referendum, uncertainty about the future stance of policy has become one of the most important issues. A broad line of research has focused on various impacts of policy uncertainty approximated by the newspaper-based measure introduced by Baker et al. (2016). Degiannakis and Filis (2019) extend this literature by evaluating monthly out-of-sample forecasts for the global policy uncertainty measure. They also examine whether ultrahigh frequency information from asset market volatilities and global economic policy uncertainty can improve the forecasts relative to the no-change forecast. The results show that the global economic policy uncertainty 
provides the highest predictive gains, followed by the European and US stock market volatilities. The results also hold when considering the directional accuracy.

Global imbalances in current accounts constitute one of the most important policy issues. In particular, the imbalances within the Eurozone and the role of the ECB and balance sheet effects are the source of great controversy. During the global financial crisis, several euro area member states with current account deficits were subject to sharp reversals of private capital flows. Kraus et al. (2019) examine how the specific policy rules of the euro area's payment system TARGET2 affect the macroeconomic adjustments to sudden stops of private capital inflows from a theoretical perspective. Kraus et al. (2019) find that-in the short run-public capital flows in form of TARGET2 help euro area deficit countries to stabilize output, consumption, and investment after a sudden stop of private capital inflows. In the long run, however, euro area countries suffer under a prolonged economic recovery and accumulated public debt as well as higher welfare compared to currencies which peg their currency to the euro.

The TARGET 2 debate emerged after several European countries with current account deficits experienced an increase in yield on government bonds. The work by Kruse and Wegener (2019) sheds some new light on this issue by testing for bubbles in those yields during the financial crisis via an assessment of the interplay between explosive behavior and long memory in the corresponding series. Kruse and Wegener (2019) consider Monte Carlo simulations and study the finite-sample properties of the popular unit root test by Phillips et al. (2011) against explosive alternatives. Their analysis proposes the usage of a set of adjusted critical values, which leads to a size-controlled test with increased power. They also consider the Lagrange Multiplier test against long memory by Tanaka (1999). The findings show that the Greek-German spread displays long memory as well as explosive behavior.

Turmoil on international markets is not a new phenomenon. In fact, several periods of banking crises can be identified since 1970. The behavior of banks during recessions is important for understanding both the transmission of international crisis and the interplay between different kinds of crises, for example, between debt and banking crisis. Asteriou et al. (2019) examine the impact of the financial crisis and economic recessions on bank shares compared to the overall stock market index for 18 OECD countries from 1993 to 2015. Based on a changes-in-changes approach, the return of the banking stock price index (treatment group) in each country is compared to their general stock price index (control group). The findings by Asteriou et al. (2019) suggest that bank returns on average perform significantly worse than that of the general stock price index during recessions. Bank share returns also display greater volatility.

Turning to general characteristics of the international financial system, two studies deal with the price of gold, which was the main cornerstone of the International Monetary System until 1973 when the system of Bretton Woods collapsed. In today's markets, gold is often characterized as a hedge or safe haven in times of uncertainty, in particular with regard to stocks. Against this background, Bampinas et al. (2019) explore the relationship between Google search activity and the conditional volatility of oil and gold spot market returns. By aggregating the volume of queries related to the two commodity markets, they construct a weekly Searching Volume Index (SVI) for each market as proxy of households and investors information demand. A rolling EGARCH framework is adopted to reveal how the significance of information demand has evolved through time. Bampinas et al. (2019) find that higher information demand increases conditional volatility in gold and oil spot market returns. The evidence shows that information flows from Google SVIs reduce the proportion of the significant volatility asymmetry produced by negative shocks in both commodity markets. The latter is more profound in the gold market. 
Murach (2018) provides a different angle in the gold market by focusing on long-run determinants. His research extends earlier work which investigated the influence of global liquidity developments on commodity prices and different asset prices. Using a multivariate cointegration analysis, he investigates long-run relationships between these variables, also controlling for macroeconomic developments in money, output and inflation on a global level. In sum, there appears to be statistical evidence of a significant influence of excess global liquidity on real gold prices and a comovement of real gold prices and inflation.

All studies highlighted the need to adopt sophisticated econometric techniques when drawing conclusions about financial market linkages and/or the effect of policy changes. They also raise several important avenues for further research, for example, with regard to the effects and transmission channels of unconventional monetary policy on financial markets.

Accepted manuscript of the following research output: Beckmann, J., Czudaj, R. L., \& Koop, G. (2019). An empirical assessment of recent challenges in today's financial markets. Scottish Journal of Political Economy, 1-4. 